\title{
Unusual accelerated rate of deletions and insertions in toxin genes in the venom glands of the pygmy copperhead (Austrelaps labialis) from kangaroo island
} Robin Doley ${ }^{\dagger}$, Nguyen Ngoc Bao Tram ${ }^{\dagger 1}, \mathrm{Md} \mathrm{Abu} \mathrm{Reza}^{1}$ and R Manjunatha Kini*1,2

Address: ${ }^{1}$ Department of Biological Sciences, Faculty of Science, National University of Singapore, Singapore 117543, Singapore and ${ }^{2}$ Protein Science Laboratory, Department of Biological Sciences, National University of Singapore, 14 Science Drive 4, Block S3, \# 03-17, 117543, Singapore

Email: Robin Doley - dbsrd@nus.edu.sg; Nguyen Ngoc Bao Tram - tram@nus.edu.sg; Md Abu Reza - rezaru@gmail.com; R Manjunatha Kini* - dbskinim@nus.edu.sg

* Corresponding author †Equal contributors

Published: 28 February 2008

BMC Evolutionary Biology 2008, 8:70 doi:10.1186/I47/-2/48-8-70

This article is available from: http://www.biomedcentral.com/I47I-2/48/8/70

(C) 2008 Doley et al; licensee BioMed Central Ltd.

This is an Open Access article distributed under the terms of the Creative Commons Attribution License (http://creativecommons.org/licenses/by/2.0), which permits unrestricted use, distribution, and reproduction in any medium, provided the original work is properly cited.
Received: 17 October 2007

Accepted: 28 February 2008

\begin{abstract}
Background: Toxin profiling helps in cataloguing the toxin present in the venom as well as in searching for novel toxins. The former helps in understanding potential pharmacological profile of the venom and evolution of toxins, while the latter contributes to understanding of novel mechanisms of toxicity and provide new research tools or prototypes of therapeutic agents.

Results: The pygmy copperhead (Austrelaps labialis) is one of the less studied species. In this present study, an attempt has been made to describe the toxin profile of $A$. labialis from Kangaroo Island using the cDNA library of its venom glands. We sequenced 658 clones which represent the common families of toxin genes present in snake venom. They include (a) putative long-chain and short-chain neurotoxins, (b) phospholipase $A_{2}$, (c) Kunitz-type protease inhibitor, (d) CRISPs, (e) C-type lectins and (f) Metalloproteases. In addition, we have also identified a novel protein with two Kunitz-type domains in tandem similar to bikunin.

Conclusion: Interestingly, the cDNA library reveals that most of the toxin families (I7 out of 43 toxin genes; $40 \%$ ) have truncated transcripts due to insertion or deletion of nucleotides. These truncated products might not be functionally active proteins. However, cellular trancripts from the same venom glands are not affected. This unusual higher rate of deletion and insertion of nucleotide in toxin genes may be responsible for the lower toxicity of A. labialis venom of Kangroo Island and have significant effect on evolution of toxin genes.
\end{abstract}

\section{Background}

Australian elapids are among the most venomous land snakes of the world. Various bioactive peptide have been purified and characterized from these venoms and a comprehensive survey of the bioactive proteins present in a number of these snake venoms have been reported recently [1]. Snakes in Austrelaps genus are widely distributed in Australia, but are moderately toxic compared to other elapids [2]. Presently three species of Austrelaps (commonly referred as copperheads) are known - Lowland copperhead (Austrelaps superbus), Highland copperhead (Austrelaps ramsayi) and Pygmy copperhead 
(Austrelaps labialis). So far, only a small number of proteins have been isolated and characterized from A. superbus venom. They are mostly phospholipase $\mathrm{A}_{2}\left(\mathrm{PLA}_{2}\right)$ enzymes [3-5] and cobra venom factor-like protein [6]. However, no significant data on the venoms of other two species are available. Pigmy copperhead (A. labialis) is smaller in size as compared to A. superbus and A. ramsayi [7] and it has distinguishable white bars to its upper lips, circular eyes and yellowish-brown iris [8]. They mainly feed on small lizards and frogs [7] and the $\mathrm{LD}_{50}$ of their venom is $1.3 \mathrm{mg} / \mathrm{kg}$ [8]. In the present study, we have attempted to profile venom components of $A$. labialis to define its composition and to look for novel proteins.

Profiling venom toxins can be achieved via transcriptomics or proteomics approach. In former approach, the transcripts are directly sequenced from a cDNA library constructed from the venom gland, whereas in the latter approach venom proteins are separated using various techniques like LCMS, 2D gel electrophoresis and HPLC. We have obtained toxin profile of pygmy copperhead venom by constructing of cDNA. The data revealed that neurotoxins and $\mathrm{PLA}_{2}$ are the most abundant proteins in this venom. Interestingly, most of the toxin families in this cDNA library have truncated transcripts. We propose that the lower venom toxicity and subsequent decreased size of these snakes could be due to unusually high degree of deletions or insertions $(\sim 40 \%)$ in their toxin genes resulting in truncated, most likely inactive products.

\section{Methods}

\section{Construction of library and DNA sequencing}

Venom glands were dissected and extracted from an euthanized A. labialis snake captured in Kangaroo Island, South Australia (Venom supplies Pte Ltd, Tanunda, South Australia). Total RNA was extracted using RNeasy ${ }^{\oplus}$ mini kit from Qiagen (Valencia, CA, USA). The purity and the concentration were spectrophotometrically determined. First strand cDNAs were synthesized from $150 \mathrm{ng}$ of total RNA according to protocol of Creator ${ }^{\mathrm{TM}}$ SMART $^{\mathrm{TM}} \mathrm{cDNA}$ library construction kit obtained from Clontech Laboratories (Palo Alto, CA, USA). Amplification of full-length double-stranded CDNA was carried out using PCR-based protocol. Double-stranded cDNA PCR products (100 bp$10 \mathrm{~kb}$ ) were purified and subjected to TA cloning. Ligation products were transformed into the competent TOP10 $\mathrm{E}$. coli strain obtained from Invitrogen (Carlsbad, CA, USA, ) and plated on LB/Amp/IPTG/X-gal for blue/white screening. A bidirectional pGEM ${ }^{\circledR}$ T Easy vector system obtained from Promega (Madison, WI, USA) plasmid-based cDNA library was titered with $0.8 \times 10^{6} \mathrm{CFU} / \mathrm{ml}$. Individual colonies were picked randomly and the presence of insert was confirmed by EcoRI digestion. Only clones containing inserts larger than $200 \mathrm{bp}$ in length were selected for further DNA sequencing.
DNA sequencing reactions were carried out using the $A B I$ PRISM $^{\circledast}$ BigDye $^{\circledast}$ terminator cycle sequencing ready reaction kit (BDV3.1) according to manufacturer's instructions (Applied Biosystem, Foster City, CA, USA). DNA sequencing was carried out using ABI PRISM ${ }^{\circledast} 3100$ automated DNA sequencer. Sequencing was repeated at least twice in all singletons to make sure there was no error created by sequencing step.

\section{Cloning snake venom protein with two Kunitz domains}

PCR amplification of protein containing two Kunitz-type domain from RNA pool was performed using a forward primer designed from the signal peptide-encoding region (5'-CGATGACGCGCGAGAAAAG-3') and the reverse primer from library construction kit (5'-ATTCTAGAGGCCGAGGCGGCCGACATG-d(T)30-3'). Long PCR enzyme mix (Fermentas, Burlington, Ont., Canada) was used in the amplification reaction. PCR was performed as follows: 35 cycles of one step each at $95^{\circ} \mathrm{C}$ for $15 \mathrm{~s}, 58^{\circ} \mathrm{C}$ for $15 \mathrm{~s}, 68^{\circ} \mathrm{C}$ for $3 \mathrm{~min}$ followed by a final extension step at $68^{\circ} \mathrm{C}$ for $10 \mathrm{~min}$. PCR products were subjected to $1 \%$ agarose gel and visualized using ethidium bromide staining. Amplified PCR products were gel purified and cloned to pGEM $^{\circledast}$-T Easy vector system and sequenced subsequently.

\section{Analysis of sequence data by bioinformatics tools}

The DNA sequences were analyzed after trimming the adaptor sequences (GENE RUNNER software) and the putative functions of the gene products were predicted by batch BLASTing sequence results in GRID blast system. The signal peptide was predicted using online SignalP 3.0 server. Clustering of sequences was performed using FastGroupII [9] and sequences were aligned using ClustalW [10]. Jalview [11] was employed to make some necessary editing on sequence alignments. Phylogenetic trees were generated using PHYML [12], which uses maximum likelihood method to build phylogenetic tree.

\section{Results and discussion \\ Compositions of CDNA library}

We randomly selected and isolated 780 clones. Of these only 658 clones, which had larger than 200 bp inserts, were sequenced and analyzed. These ESTs were categorized into different clusters on the basis of sequence similarities. Members of each clusters has been sequenced completely and the full length sequences were submitted to NCBI with accession numbers from EU003085 to EU003110, EU012449 and EU012450. BLAST search against nucleotide, protein and EST database, revealed that $60 \%$ of the EST belong to putative toxins, while $32 \%$ belong to cellular transcripts and $8 \%$ of the EST were unknown transcripts (Fig. 1A). These relative ratios may change, if more EST clones are sequenced and analyzed. 


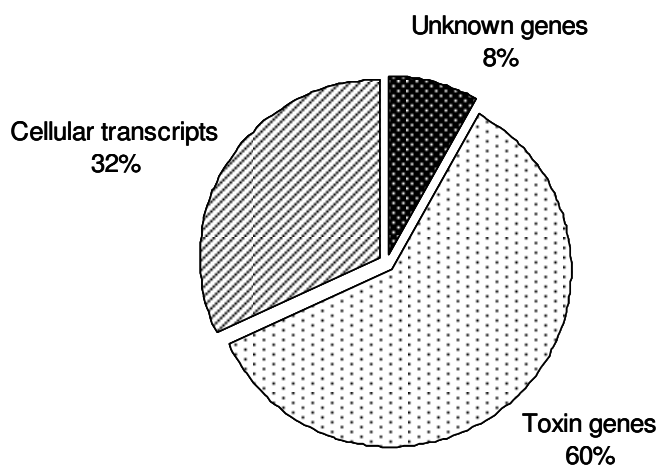

A

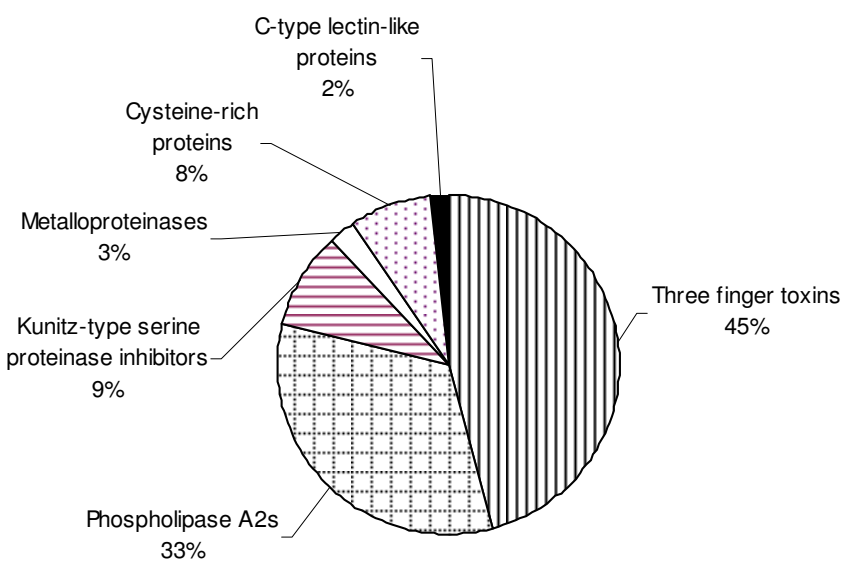

B

Figure I

Composition of a cDNA library from A. labialis venom gland. A) Relative abundance of genes sequenced from the cDNA library; B) Relative abundance of the toxin genes in the cDNA library.

\section{Toxin genes}

Putative toxin genes found in the cDNA library were further grouped based on their sequence similarities to known toxin superfamilies (Fig. 1B). In total, we found six superfamilies of the toxin genes in the cDNA library of $A$. labialis. These families, in order of abundance, are threefinger toxin family (193 clones), phospholipase $A_{2}$ family (139 clones), Kunitz-type proteinase inhibitor family (38 clones), cysteine-rich protein family (32 clones), metalloproteinase family (12 clones) and C-type lectin family (7 clones) (Fig. 1B).

\section{Three-finger toxin family}

Three-finger toxin family is a well characterized non-enzymatic polypeptide family named after their canonical protein folds. Members of this family contain about 60-74 amino acid residues [13-16] and exhibit various pharmacological activities such as neurotoxic, cytotoxic, cardiotoxic, anticoagulant and antiplatelet effects [13-15]. Three-finger family forms the major group of toxins (45\% abundance) in this cDNA library, and majority of mature proteins are 66-69 amino acid residues in length. We identified a total of 166 sequences ( 8 clusters and 10 singletons) with $60 \%-80 \%$ identities to known long-chain neurotoxins (Figure 2A) and 27 sequences (1 cluster and 1 singleton) with $60 \%-85 \%$ identical to short-chain neurotoxins (Figure $2 \mathrm{~B}$ ).

\section{Long-chain neurotoxins}

Clone $8 \mathrm{~A}$ (80 clones) is the most dominant long-chain neurotoxin and other clones $(208,23 \mathrm{~B}, 10 \mathrm{~B}, 92,464,458$ and 26B) are its isoforms with few amino acid substitutions (Figure 2A). Most of these substitutions are due to single nucleotide changes. Since these isoforms are represented by many clones, these sequence differences are not artifacts of sequencing. However, clone 5B has 10 substitutions and hence may have distinct specificity compared to other long-chain neurotoxins. Further, a dinucleotide (GT) deletion in front of the typical stop codon position followed by a dinucleotide (CT) insertion (Additional file 1 ) in the gene resulted in a frame shift and additional five amino acid residues in clone 5B (Figure 2A). However, two clones (160 and 646) are distinctively shorter due to deletion of nucleotides A131 and G111 respectively (see Additional file 1), resulting in the frame shift and truncated peptides.

There were eight clones identical to clone 160 suggesting that this observation is not due to sequencing error. The segments after the deletion show significant identity with other complete transcripts. Similar phenomenon was observed in sea snake Aipysurus eydouxii in which a dinucleotide deletion leads to the truncation of the only threefinger neurotoxin found in the venom gland library and the loss of toxicity [17]. In contrast, in clone 112 deletion of A224 leads to a potentially much longer protein product. In this case, three of the conserved cysteine residues at the C-terminal end are lost due to the frame shift. Three distinct neurotoxin sequences (clones 21, 242 and 509) compared to clone $8 \mathrm{~A}$ and its closer sibling toxins were also found in the cDNA library. Clones 21 and 242 encode for slightly longer proteins with 75 and 86 amino 
A

\begin{tabular}{|llcl}
\hline$\alpha-C o b r a:$ & &
\end{tabular}

B

\begin{tabular}{|c|c|c|c|}
\hline & & $\star \star \star \star \square^{*}$ & \\
\hline Erabtx_a & MKTLLLTLVVVTIVCLDLGYTRICFNHQSSQPQTTKTC & PGESSCYNKQWSDFRGTIIERGCGCPTVKPGIKLSCCESEVCNN & 83 \\
\hline $6 \mathrm{~A} \quad 21$ & MKTLLLTLVVVTIVCLDLGYTMTCCNQQSSQPKTTTTC & TESSCYKKTWRDHRGT I IERGCGCPNVKPGVQLVCCETNECNN & 81 \\
\hline $12 \mathrm{~B} 1$ & MKTLLLTLVVVTIVCLDLGYTMTCCNQQSSQPKATTTC & TESSCYKKTWRDHRGTI IERGCGCPNVKPGVQLVCCETNECNN & 81 \\
\hline
\end{tabular}

Figure 2

Three-finger toxins in A. labialis venom gland. A) Alignment of long-chain neurotoxins with $\alpha$-cobratoxin ( $\alpha$-cobra) [64]. The changed in amino acids are highlighted in grey which is either due to addition or deletion of nucleotide. $\bullet$, conserved Cysteine residues; *, residues involved in binding to nicotinic acetylcholine receptor (nAChR); and $\square$, residues Ala28 and Lys49 involved in binding to $\alpha 7$ receptor and $n A C h R$ receptor, respectively. Residues that are different from consensus sequence of A. lablialis toxins are highlighted. The truncated transcripts and the elongated protein product (clone II 2; for brevity, functionally unimportant parts of the sequence are not shown and the dots indicate the missing segments). The number of clones is shown in italics and the predicted signal peptide using SignalP 3.0 is underlined (The signal peptide for $\alpha$-cobrotoxin is not available). B) Alignment of two cDNA-deduced peptide representatives of one cluster and one singleton of putative short-chain neurotoxin with Erabutoxin a (Erabtx_a) [65]. The gaps in clone 6A and I2B are represented by blank spaces. *, residues involved in binding to nicotinic acetylcholine receptor ( $\mathrm{AChR}$ ). The substitution of Thr to Ala in clone I2B is highlighted. Phe32 $(\square)$ of erabutoxin a involved in binding to nAChR receptor which is substituted with His 32 in both the clones of $A$. labialis is highlighted. The number of clones is shown in italics and the predicted signal peptide using SignalP 3.0 is underlined.

acid residues respectively as compared to other clones. In these cases there is a single nucleotide substitution at consensus stop codon (TAA) present in the majority of these putative long-chain neurotoxins. In clone 509, a dinucleotide (TA) deletion in the stop codon followed by a dinucleotide (CA) insertion and a dinucleotide deletion (AC) has been found.

Most of the putative full length long-chain neurotoxins possess the functionally conserved residues such as Lys23, Trp25, Asp27, Phe29, Arg33 and Lys35 that are shown to participate in the binding to Torpedo nicotinic acetylcholine receptor $(\mathrm{nAChR})$ in the case of $\alpha$-cobratoxin from Naja naja venom [18]. However, Lys49 (corresponding to position 50 in A. labialis toxins) is replaced by the negatively charged Glu50 (Figure 2A). This charge reversal may significantly reduce its interaction with Torpedo nAChR as mutation of K49 to E49 in $\alpha$-cobratoxin cause 53 fold decrease in binding affinity [18]. Further, neutrally charged Ala28 (corresponding to position 29 in A. labialis toxins) which is specific for binding to $\alpha 7-n A C h R$ in $\alpha$ cobratoxin, is replaced by the positively charged Arg29 with the exception of clone 5B (Figure 2A). This substitution did not affect the binding affinity to the receptor in the case of $\alpha$-cobratoxin [19].

The majority of A. labialis long-chain neurotoxins form a distinctive group almost completely separated from the other long-chain neurotoxins (Figure 3). Phylogenetically, this separation seems to start quite early in the evolution time frame as indicated by early branching pattern originating from the root. Interestingly, three distinct 


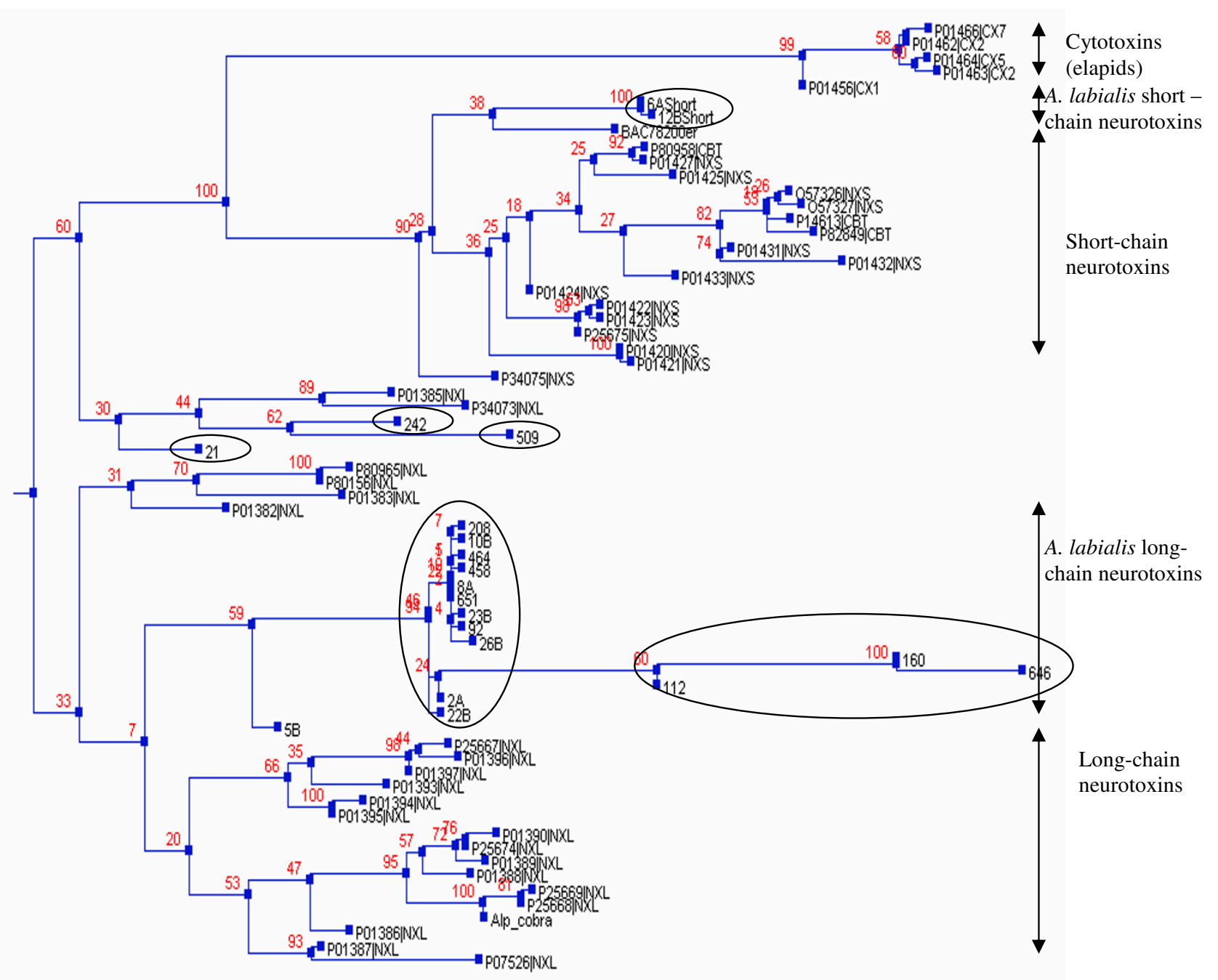

Figure 3

Phylogenetic tree of elapid three-finger toxins. Full length A. labialis long-chain and short-chain neurotoxins are encircled. Phylogram was generated by PHYML using maximum likelihood method.

clones (21, 242 and 509) form a separate cluster as compared to other long-chain neurotoxins and appear to have a completely different phylogenetic origin.

\section{Short-chain neurotoxins}

Two representatives of short-chain neurotoxins, Clone 6A and $12 \mathrm{~B}$ were found in the library (1 cluster with 21 clones and 1 singleton respectively). Their amino acid sequences are identical except for the substitution of Thr13 by Ala. Both short-chain neurotoxins have one additional Cys residue at the fourth position (Figure 2B). Appearance of Cys at $4^{\text {th }}$ position is observed for shortchain neurotoxins from sea snake venom [20]. They have functionally invariant residues such as Lys27, Trp29,
Asp31, Arg33 and Lys47 which are important in the binding of erabutoxin a (Laticauda semifasciata) to Torpedo $\mathrm{nAChR}[21,22]$. Interestingly, one of the binding residues, Phe32 found in erabutoxin-a, is replaced by His in A. labialis short-chain neurotoxins which might effect its binding to the receptor.

\section{Phospholipase $A_{2}$ family}

Phospholipase $\mathrm{A}_{2}\left(\mathrm{PLA}_{2}\right.$; EC 3.1.1.4) enzymes are esterolytic enzymes which hydrolyze glycerophospholipids at the $s n-2$ position of the glycerol backbone releasing lysophospholipids and free fatty acids. Snake venom PLA 2 enzymes are one of the well studied superfamily of snake venom enzymes [23] which play an important role in 
immobilization and capture of prey. In addition to their role in digestion of preys, they exhibit variety of pharmacological effects such as neurotoxic, myotoxic, cardiotoxic, anticoagulant, antiplatelet and edema-inducing effects [24]. A total of $139 \mathrm{PLA}_{2}$ cDNA clones were obtained which makes up the second abundant family. The deduced amino acid sequences are $65 \%$ to $97 \%$ identical to other $\mathrm{PLA}_{2}$ sequences and were grouped into three clusters and four singletons. All PLA ${ }_{2}$ CDNA sequences obtained from this snake belong to group IA.

Clones 243, 330, 563 and 488 are the most abundant clones in this library and are closely related to the PLA sequences of $A$. superbus [5] of the same genus. However, they are different from the other PLA ${ }_{2}$ enzymes due to the presence of three tryptophan residues in the $\beta$-wing. At present, role of these Trp residues are not known. These $\mathrm{PLA}_{2}$ enzymes together with five PLA ${ }_{2}$ isoforms of $A$. superbus (AAD56550, AAD56551, AAD56552, AAD56553, and AAD56554) [5] form a distinguishable cluster shown in phylogram generated by PHYML method (data not shown). This cluster is well separated from the other $\mathrm{PLA}_{2}$ enzymes having one tryptophan residue in the $\beta$-wing.

Clones 518 and 636 have significant difference in amino acid sequences of other $A$. labialis PLA $_{2}$ enzymes. Clone 636 encodes for the full length protein sequence, whereas clone 518 encodes for a truncated product due to a single nucleotide (A) addition at position 247 (Additional file 2) (from ATG) leading to frame shift and premature truncation (Figure 4). These clones form a distinct cluster along

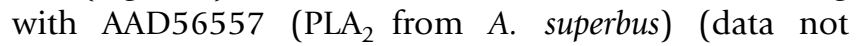
shown).

\section{Kunitz-type serine protease inhibitor family}

Kunitz-type of protease inhibitors are 60 residues long which possess the conserved sequence motif of 6 cysteines (C [8X]C [15X]C [4X]YGGC [12X]C [3X]C) [25] and functionally belong to bovine pancreatic trypsin inhibitor (BPTI) family [26]. This family of snake venom protein is known to involve in coagulation, fibrinolysis and inflammation through interaction with various proteases [27].

38 cDNA clones in this library belong to Kunitz-type serine protease inhibitor family. The sequences of this group are $77 \%-90 \%$ identical to mulgin isoforms (Pseudechis australis) and textilinin isoforms (Pseudonaja textilis textilis) (Figure 5A). Textilinins are shown to be distinct plasmin inhibitors and have a $60 \%$ bleeding reduction in murine model [28]. It will be interesting to study the role of these Kunitz-type serine proteases inhibitors in blood clotting cascade. However one of the clones, clone 602 was found to be truncated prematurely due to transversion of one nucleotide $(\mathrm{A} \rightarrow \mathrm{T}$ ) at position 122 (from AAA encoding for Lys to TAA stop codon). This clone was resequenced to confirm the transversion is not due to sequencing error.

A unique clone (655) encoding protein with two tandem Kunitz-type protease inhibitor domains was found in this cDNA library. The entire cDNA sequence is $2,031 \mathrm{bp}$ long (Figure 5B) and the deduced peptide has 252 amino acid residues with potential glycosylation site. Its presence was further confirmed by PCR using gene specific and reverse primer from cDNA construction kit. We sequenced 48 clones and seven isoforms with minor changes in the amino acid sequence were found (Figure 5C). They are $40 \%$ identical to bikunin, a serine proteinase inhibitor with two Kunitz domains [29]. Bikunin from human pla-

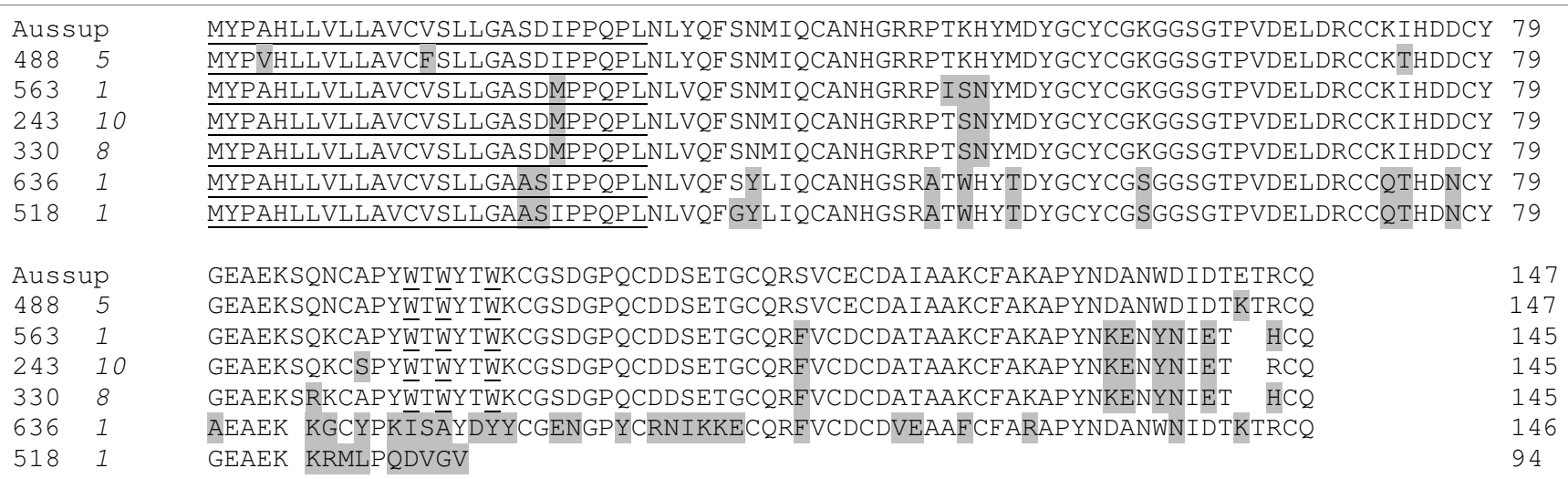

\section{Figure 4}

Phospholipase $\mathbf{A}_{2}$ enzymes in A. labialis venom gland. Alignment of PLA $A_{2}$ enzymes from A. labialis with A. superbus (Aussup) [5] is shown. Residues that are different from $A$. superbus $P_{2} A_{2}$ are highlighted. The three Trp (W) residues present in the

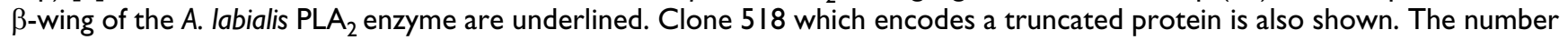
of clones is shown in italics and the predicted signal peptide using SignalP 3.0 is underlined. 
A

\begin{tabular}{|c|c|c|}
\hline Textilinin & 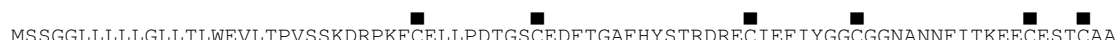 & $83+2>$ \\
\hline Mulgin-2 & 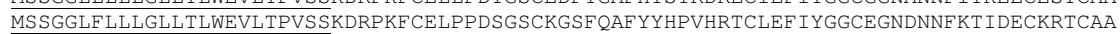 & 83 \\
\hline 28 & MSSGGLLLLLGLLTLWEVLTPVSSKDRPKFCKLPADTGRCKGKF P̂AFYYHPVHRTCLEF IYGGCEGNPNNFKTIDECERTCAV & 83 \\
\hline 4911 & MSSGGLLLLLGLLTLWEVLTPVFSKDRPKFCKLPADTGRCKGKFPAFYYHPVHRTCLEF IYGGCEGNPNNFKTIDECERTCAV & 83 \\
\hline 5888 & $\frac{1}{M S S G G L L L L L G L L T L W E V L T P V S S K D R P K F C K L P A D T G R C K G K F P A F Y Y H P V H R T C L E F ~ I ~ G G C E G N P N N F K T ~ I D E C E R T C A V ~}$ & 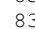 \\
\hline 1194 & MSSGGLLLLLGLLTLWEVLTPVSSKDRPKFCELAADTGPCKAKF QAFYYHPVHRTCLEF I YGGCEGNANNFKTIDECKRTCAA & 83 \\
\hline 2603 & MSSGGLLLLLGLLTLWEVLTPVSSKDRPKFCELAADT GPCKAKF QAFYHHPVHRTCLEF I GGGCEGNANNFKT IDECKRTCAA & 83 \\
\hline 5611 & MSSGGLLLLLGLLTLWEVLTPVSSKDRPKFCELAADTGPCKAKF QAFYYHPVHRTCLEF I YGGCEGNANNFKTIDECKRPCAA & 83 \\
\hline 18B 1 & MSSGGLLLLLGLLTLWEVLTPVSSKDRPHFCHLPHDTGPCKRNTQAFYYNPVYHTCLKF IYGGCEGNANNFKTIDECKRTCAT & 83 \\
\hline 5681 & $\frac{1}{M S S G G L L L L L G L L T L W E V L T P V S S K D P E F C E L P A D S G S C K G N F Q A F Y Y N P V O H O C L E F ~ I ~ G G G C D ~ G N A N N F K T I D E C K R T C A A ~}$ & 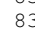 \\
\hline 6021 & $\begin{array}{l}\text { MSSGGLLLLLGLLTLWEVLTPVSSKDRPKFCKLPADTGRC } \\
\text { MSTER }\end{array}$ & 40 \\
\hline
\end{tabular}

B

\begin{tabular}{|c|c|c|}
\hline $\begin{array}{l}\text { Bikunin } \\
655\end{array}$ & $\begin{array}{l}\text { MAQLCGLRRSRAFLALLGSLLLSGVLAADRERSIHDFCLVSKVVGRCRASMPRWWYNVTDGSCQLFVYGGCDGNSNNYLTKEECLKKCATVTENAT } \\
\begin{array}{llll}\text { MTREKS LALL } & \text { ITLAAALAAAE } & \text { SPPGRCHSPKTVGPCRASFHRWRYNATSQMCQEFIFGGCKGNANNFVSKODCFQTCIRG GAAE }\end{array}\end{array}$ & $\begin{array}{l}96 \\
84\end{array}$ \\
\hline $\begin{array}{l}\text { Bikunin } \\
655\end{array}$ & $\begin{array}{l}\text { GDLATSRNAADSSVPSAPRRQDSEDHSSDMFNYEEYCTANAVTGPCRASFPRWYFDVERNSCNNFIYGGCRGNKNSYRSEEACMLRCFRQ } \\
\text { ATVVPSGPATEVATPRAGHLPEAYENRP }\end{array}$ & $\begin{array}{l}188 \\
177\end{array}$ \\
\hline Bikunin & LGSKVVVLAGLFVMVLILFLGASMVYLIRVARRNQERALRTVWSSGDDKEQLVKNTYVL & 252 \\
\hline 655 & PGDAGAQPPLPSEPF SF STRAVVLAVLPAI LVT I LLGSMGVF FVKICRKNPELSVGTVWSTLDDKEYLMSNAYTL & 252 \\
\hline
\end{tabular}

C

\begin{tabular}{|c|c|c|}
\hline 655 & MTREKSLALLITLAAALAAAESPPGRCHSPKTVGPCRASF HRWRYNATSQMCQEF IFGGCKGNANNFVSKQDCFQTCIRGGAAEATVVPSGPATEV & 96 \\
\hline 65546 & MTREKSLALLITLAAALAAAESPPGRCHSPKTVGPCRASF HRWWHNATSQMCQEF IFGGCKGNANNFVSKQDCFQTCIRGGAAEATVVPSGPATEV & 96 \\
\hline 65531 & MTREKSLALLITLAAALAAAESPPGRCHSPKTVGPCRASF HRWWYNATSQMCQEF IFGGCKGDANNFVSKQDCFQTCIRGGAAEATVVPSGPATEV & 96 \\
\hline 65508 & MTREKSLALLITLAAALAAAESPPGRCHSPKTVGPCRASF HRWWYNATSQMCQEF IFGGYKGNANNFASKQDCFQTCIRGGAAEATVVPSGPATEV & 96 \\
\hline 65518 & MTREKSLALLITLAAALAAAESPPGQCHSPKTVGPCRASF HRWWYNATSQMCQEF IFGGCKGNANNFVSKQDCFQTCIRGGAAEATVVPSGPATEV & 96 \\
\hline 65512 & MTREKSLALLITLAAALAAAESPPGRYHSPKTVGPCRASF HRWWYNATSQMCQEF IFGGCKGNANNFVSKQDCFQTCIRGGAAEATVVPSGPATEV & 96 \\
\hline \multirow[t]{2}{*}{65513} & MTREKS LALLITLAAALAAAE SPP GRCHSPKTVGPCRASF HRWWYNAT SQMCQEF IF GGCKGNANNFVSKQDCF QTCIRGGAAEATVVP S GPATEV & 96 \\
\hline & 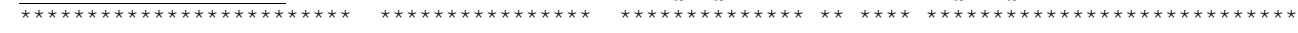 & \\
\hline 65500 & ATPRAGHLPEAYENRPGFREFCAAPRVVGPCRASF LRWYFDLESRMCKMFIYGGCRGNKNNYLFEEHCWSQCTGDGEITEEPGDAGAQPPLPSEPF & 192 \\
\hline 65546 & ATPRAGHLPEAYENGPGFREFCAAPRVVGPCRASF LRWYFDLESRMCKMF I YGGCRGNKNNYPFEEHCWSQCTGDGEITEEPGDAGAQPPLPSEPF & 192 \\
\hline 65531 & ATPRAGHLPEAYENRPGEREFCAAPRVVGPCRASF LRWYFGLESRMCKMF IYGGCRGNKNNYLFEEHCWSQCTGDGEITEEPGDAGAQPPLPSEPF & 192 \\
\hline 65508 & ATPRAGHLPEAYENRPGFREFCAAPRVVGPCRASFLRWYFDLESRMCKMFIYGGCRGNKNNYLFEEHCWSQCTGDGEITEEPGDAGAQPPLLSEPF & 192 \\
\hline 65518 & ATPRAGHLPEAYENRPGFREFCAAPRVVGPCRASFLRWYFDLESRMCKMFIYGGCRGNKNNYLFEEHCWSQCTGDGEITEEPGDAGAQPPIPSEPF & 192 \\
\hline 65512 & ATPRAGHLPEAYENRPGFREFCAAPRVVGPCRASF LRWYFDLESRMCKMF I YGGCRGNKNSY LFEEHCWSQCTGDGEI TEEPGDAGAQPPLPSEPF & 192 \\
\hline \multirow[t]{2}{*}{65513} & 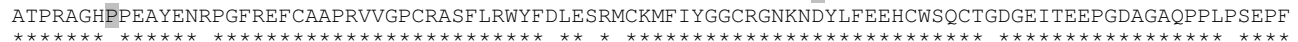 & 192 \\
\hline & 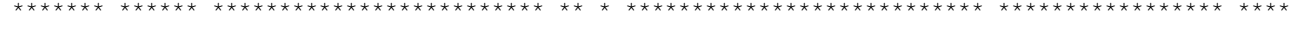 & \\
\hline 65500 & SFSTRAVVLAVLPAILVTILLGSMGVFFVKICRKNPELSVGTVWSTLDDKEYLMSNAYTL & 252 \\
\hline 65546 & SFSTRAVVLAVLLAILVTILLGSMGVFFVKICRKNPELSVGTVWSTLDDKEYLMSNAYTL & 252 \\
\hline 65531 & SFSTRAVVLAVLLAILVTILLGSMGVFFVKICRKNPELSVGTVWSTLDDKEYLMSNAYTL & 252 \\
\hline 65508 & SFSTRAVVLAVLLAILVTILLGSMGVFFVKICRKNPELSVGTVWSTLDDKEYLMSNAYTL & 252 \\
\hline 65518 & SFSTRAVVLAVLLAILVTILLGSMGVFFVKICRKNPELSVGTVWSTLDDKEYLMSNAYTL & 252 \\
\hline 65512 & SFSTRAVVLAVLLAILVT I LLGSMGVFFVKICRKNPELSVGTVWSTLDDKEYLMSNAYTL & 252 \\
\hline \multirow[t]{2}{*}{65513} & SFSTRAVVLAVLLAILVTILLGSMGVFFVKICRKNPELSVGTVWSTLDDKEYLMSNAYTL & 252 \\
\hline & ㅊㅊ & \\
\hline
\end{tabular}

\section{Figure 5}

Serine protease inhibitors in A. labialis venom gland. A) Alignment of Kunitz-type serine protease inhibitors. $\mathbf{\square}$, conserved six cysteine residues in kunitz domain. Residues that are different from the consensus sequence of $A$. labialis proteins are highlighted. The number of clones is shown in italics and the predicted signal peptide using SignalP 3.0 is underlined. B) Alignment of clone 655 (serine protease inhibitor containing two Kunitz domains) with bikunin [29]. Signal peptide of clone 655 is indicated by a vertical bar ( | ), $\mathbf{0}$, conserved six cysteine residues; $\square, \mathrm{N}$-glycosylation site. Conserved residues are highlighted. C) Alignment of isoforms of two Kunitz-type domains. The presence of two Kunitz-type domains was further confirmed by PCR using gene specific primer and reverse primer from cDNA construction kit (for details, see Materials and methods). *, consensus residues and residues that are different from the consensus sequence are highlighted. The number of clones is shown in italics and the predicted signal peptide using SignalP 3.0 is underlined. 
centa exhibits a potent inhibitory effect to some serine proteases crucial in the blood coagulation and fibrinolysis, such as factor XIa and plasmin [30]. This is the first report of this novel member of Kunitz-type serine protease inhibitor family from snake venom.

\section{Cysteine-rich protein family}

Cysteine-rich secretory proteins (CRISPs) are abundantly found in mammalian reproductive tracts and play important role in sperm maturation and immune system [31]. They have also been found in venoms of reptiles. The conserved sequence in CRISPs span through out the protein with 16 cysteine residues and 10 of them resides in the Cterminal end [32]. CRISPs have been purified and characterized from various snake venoms [32,32-34]. Functions of majority of these proteins are unknown. Some of them are known to block cyclic nucleotide-gated ion channels $[35,36]$ while several others block potassium-stimulated smooth muscle contraction [33].

32 cDNA clones encoding CRISPs making up $8 \%$ of the library has been observed. This family has one cluster and four singletons (Figure 6). Clone 521 has a dinucleotide deletion (CT) in position 549 and series of single nucleotide deletion of A in positions 537, 579, 595 and 597, single nucleotide deletion of $\mathrm{T}, \mathrm{C}$ and $\mathrm{G}$ at position 575 ,
606 and 623 respectively. Clone 218 has two single nucleotide deletions of A579 and A648. Clone 492 has also two single nucleotide deletions of A579 and G623. Clones 217 and 399 have an insertion of one A at position 349 while clone 399 has another insertion of $\mathrm{T}$ in position 483. In case of clone 363 there is an insertion of $\mathrm{T}$ and $\mathrm{A}$ at position 341 and 349, deletions of T572, A579, A605, A610 and A621 (Additional file 3). Due to these insertions in clone 217 and 399 C-terminal end has encoded different amino acid residues as compared to other CRISPs. Clones 521, 218, 492 and 363 have several deletions in the ORF leading to frame shift and premature truncation. Thus, all of them are prematurely terminated losing the C-terminal domain where most of the conserved cysteine residues are found (Figure 6). Thus the truncated transcript might not be functional. However, the N-terminal region have high identity to snake venom CRISPs (53\%-94\%), but low identity to human, murine, frog CRISPs (less than 40\%).

\section{Metalloproteinase family}

Snake venom metalloproteinases are more abundantly found in viper venoms, but they are also reported from elapid family $[37,38]$. They are synthesized as zymogens in the venom gland and contain a propeptide which is cleaved off during maturation. They have a common zinc

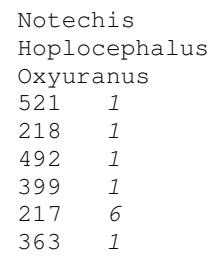

Notechis Hoplocephalus oxyuranus

521

$\begin{array}{ll}521 & 1 \\ 218 & 1\end{array}$

4921

3991

2176

3631

Notechis Hoplocephalus

oxyuranus

521

$218 \quad 1$

$492 \quad 1$

3991

$\begin{array}{ll}217 & 6 \\ 363 & 1\end{array}$

\section{Figure 6}

Alignment of CRISPs from A. labialis Notechis scutatus, Hoplocephalus stephensii, Oxyuranus microlepidotus [66]. $\square$, conserved cysteine. Residues that are different from the majority of sequences are highlighted. The number of clones is shown in italics and the predicted signal peptide using SignalP 3.0 is underlined.

MIAFIVLLSLAAVLQQSSGTVDFASESSNKKDYQKEIVDKHNALRRSVKPTARNMLRMEWNSHAAQNAKRWADRCTFAHSPPHTRTVGKLRCGENI 96 MIAFIVLLSLAAVLQQSSGTVDFASESSNKKDYQKEIVDKHNALRRSVKPTARNMLRMKWNSRAAQNAKRWADRCTFAHSPPHTRTVGKLRCGENI 96 MIAF IVLLSLAAVLQQSSGTVDFASESSNKKDYRKEIVDKHNDLRRSVKPTARNMLQMKWNSRAAQNAKRWANRCTFAHSPPYTRTVGKLRCGENI 96 MIAF IVLLSLAAVLQOSSGTVDFASESSNKKDYRKEIVDKHNALRRSVKPTARNMLQMEWNSRAAQNAKRWADRCTFAHSPPHTRTVGKLRCGENI 96 MIAFIVLLSLAAVLQQSSGTVDFASESSNKKDYRKEIVDKHNALRRSVKPTARNMLQMEWNSRAAQNAKRWADRCTFAHSPPHTRTVGKLRCGENI 96 MIAFIVLLSLAAVLQQFSGTVDFASESSNKKDYRKEIVDKHNALRRSVKPTARNMLQMEWNSRAAQNAKRWADRCTFAHSPPHTRTVGKLRCGENI 96 MIAFIVLLSLAAVLQQSSGTVDFASESSNKKDYRKEIVDKHNALRRSVKPTARNMLQMEWNSRAAQNAKRWADRCTFAHSPPHTRTVGKLRCGENI 96 MIAFIVLLSLAAVLQQSSGTVDFASESSNKKDYRKEIVDKHNALRRSVKPTARNMLQMEWNSRAAQNAKRWADRCTFAHSPPHTRTVGKLRCGENI 96 MIAFIVLLSLAAVLQQSSGTVDFASESSNKKDYRKEIVDKHNALRRSVKPTARNMLQMEWNSRAAQNAKRWADRCTFAHSPPHTRTVGKLRCGENI 96

FMSSQPFAWSGVVQAWYDEVKKFVYGIGAKPPGSVIGHYTQVVWYKSHLLGCASAKCSSTKYLYVCQYCPAGNIRGSIATPYKSGPTCGDCPSACV 192 FMSSQPFAWSGVVQAWYDEVKKFVYGIGAKPPGSVIGHYTQVVWYKSHLLGCASAKCSSTKYLYVCQYCPAGNIRGSIATPYKSGPPCADCPSACV 192 FMSSOPFAWSGVVQAWYDEVKKFVYGIGAKPPSSVIGHYTQVVWYKSHLLGCASAKCSSTKYLYVCQYCPAGNIIGSIATPYKSGPPCGDCPSACD 192 FMSTQPFAWSGVVQAWYDEVKKFVYGIGAKPPGSVIGHYTQVVWYKSHLLGCASAKCSSTKYLYVCQYCPAGNIRGSIATPYNQAR WWDCPSAGS 191 FMSTQPFAWSGVVRAWYDEVKKFVYGIGAKPPGSVIGHYTQVVWYKSHLLGCASAKCSSTKYLYVCQYCPAGNIRGSIATPYKSGPACGDCPSACV 192 FMSTQPFAWSGVVQAWYDEVKKFVYGIGAKPPGSVIGHYTQVVWYKSHLLGCASAKCSSPKYLYVCQYCPAGNIRGS IATPYKSGPAWGDCPSACV 192 FMPTQPFAWSGVVQAWYDEVKKIRLWHWSKATRF CYWPLYPGSLVQKSPSWLCFCQMFFNQIPLRLS-ILPQGTSEVQLLLHINQGQLVGTVLRL 190 FMPTQPFAWSGVVQAWYDEVKKIRLWHWSKATRF CYWPLYPGSLVQKSPSWLCFCQMFFNQIPLRLS-ILPSREHQRFNCYSI FMSTQPFAWSGVVRAWYD

-

NGLCTNPCKYEDDF SNCKALAKNSKCQTEWIKSKCPAACFCHNKII

NGLCTNPCKHEDDF SNCKALAKNSKCQTAWIKSKCPATCFCHNKI I

NGLCTNPCKHNDDLSNCKPLAKKSKCOTEWIKSKCPATCFCRTEII RTMPNLAK

TDYAQILANMKMPSR TALWRKN

TDYAQI LADMKMPSQLQGFTEKN

YAQSLQNMKMPSRTAKLVSPD 


\begin{abstract}
LIBf MGHFTF IGLCLLAMFLSLSGAECYTCP IDWLPKNGLCYKVF SNPKSWLDAEMFCRKFKPGCHLAS IHRDADSADLAE LBm MGHFTFTGLCLLAMFLSLRGAECYTCP IDWLPKNGLCYKVF SNPNTWLDAELFCRKFKPGCRLASLHRDADSADLAE BfL MGHFTF IGLCLLAMF LSLSGAECYTCP IDWLPKNGLCYKVF SKHKTWF DAEMYCRKFKPGCHLASLHSNADAVEF SE TSL MGRFIFVSFGLLVVFLSLSGAKGSCCTNDS LPMNGMCYKIFDEPKTWEDAEMFCRKYKPGCHLASF HRLAESLDIAE 1327 MGRFLLVTLSLLVVAF SLNEANGSCCPQDWLPKNGFCYKVFNDLKNWDDAEMFCRKFKPGCHLAS I HSNADSADLAE

\section{Figure 7}

Alignment of A. labialis C-type lectin (clone I32) with LIBf (Bungarus fasciatus), LBm (B. multicinctus), BFL2 (Bungarus fasciatus) and TsL (Trimeressurus stejneger) [47,53] GIn-Pro-Asp (QPD) sequence essential for galactose interaction is indicated by box and region flanked by $(-)$ and $(4)$ are residues essential for $\mathrm{Ca}^{2+}$ interaction [67]. The number of clones is shown in italics and the predicted signal peptide using SignalP 3.0 is underlined.

binding site with a consensus sequence of HEXXHXXGXXH [39]. They are classified into different types (PI to P-IV) on the basis of the other domains that are present in these complexes [40]. This family of enzymes are responsible for haemorrhagic [41,42], local myonecrotic [43], antiplatelet [44], edema-inducing and other inflammatory effects $[45,46]$. We have found 12 clones which makes $3 \%$ of the entire cDNA library, however they code for only the signal peptide and the N-terminal region similar to trigramin precursor and mocarhagin (data not shown). This is due to the loss of two nucleotides at position 316 downstream of ATG leading to premature termination of the protein. Thus, if proteins of this family are present in the venom, they would have only partial propeptide without any other functional domains of metalloproteinase or disintegrin.

\section{C-type lectin family}

C-type lectins are non-enzymatic proteins that bind to mono- and oligosaccharides in presence of $\mathrm{Ca}^{2+}$ [47]. Generally they contain the highly conserved domain called the carbohydrate recognition domain (CRD) [48]. C-type lectins and related proteins have been frequently reported from Viperidae snake venoms. Venom C-type lectin related proteins are known to disrupt the normal functioning of haemostatic mechanism by interfering in the normal platelet receptor-ligand interaction, binding to coagulation factors and other important proteins in coagulation cascade [48]. Only few of them have been reported from elapids [49-53] including Australian elapids [54].

This family has seven clones which form one cluster. The primary structure shows $71 \%$ and $74 \%$ identical to C-type lectins found in Bungarus fasciatus and B. multicinctus [53], $56 \%$ identical to galactose-binding lectin found in Bitis arietans [55], but less than 37\% identical to C-type lectin related proteins. The deduced amino acid sequence reveals the conserved carbohydrate binding domain as well as the $\mathrm{Ca}^{2+}$ interaction amino acid residues (Figure 7 ). The odd cysteine present is likely to involved in interchain disulphide bond $[50,55]$. The presence of only one cluster of 7 clones indicates that it may exist as homodimer similar to other C-type lectins. Further, phylogenetic analysis (data not shown) revealed that this putative C-type lectin is more closely related to galactosebinding proteins and forms a cluster distinct from that of C-type lectin like proteins that bind to blood coagulation factors or platelet receptors. Thus, this clone most likely encodes a homodimeric C-type lectin.

\section{Cellular transcripts}

150 clones were identified as cellular trancripts which were grouped into 15 clusters and 1 singleton which constituted $32 \%$ of the entire library (Figure 1A). This suggests that harvesting the venom gland after 3-4 days after milking increases the chances of obtaining mostly high abundant toxin genes. We identified ribosomal proteins, creatine kinase, dehydrogenase, muscle troponin, cytochrome b, parvalbumin, heparin binding protein and protein disulphide isomerase (PDI) in this library. In addition, polyadenylated $12 \mathrm{~S}$ and $16 \mathrm{~S}$ rRNAs were also found. Although polyadenylation is the distinctive features of mRNA, polyadenylation of rRNA has been observed in yeast [56], Leishmania [57] as well as in other higher organisms including human [58]. These polyadenylated rRNAs are degraded subsequently through Polyadenyled-stimulated RNA degradation pathway $[56,58]$. 


\section{Unknown sequences}

$8 \%$ of the cDNA sequences (Figure 1A) of the library did not show any significant match to toxins or other metabolic genes and hence were categorized as unknown sequences. Bioinformatics analysis of these sequences showed only partial or poor homology to protein sequences of other organism. Their functional role is not known.

\section{Accelerated rate of deletions and insertions in toxin genes} Evolution of large multigene families in snake venom occurs through "birth and death" process [59]. Toxin genes appear to undergo duplication followed by accelerated evolution to give rise to new genes [60]. Some of the genes either get deleted from the genome due to unequal cross-over and other phenomena or become non-functional and degenerate into pseudogenes [61]. Such birth and death phenomenon allows the snake to adapt to target various preys. In A. labialis, we observed unusually accelerated rate of deletions and insertions in toxin cDNA clones resulting in the death of functional toxin genes. Out of the 43 cDNAs encoding toxins (Table 1), only 26 encode full length proteins. A total of 17 cDNAs encode for truncated products due to deletions (10 genes) or insertions ( 7 genes). Thus $39.5 \%$ of the toxin cDNAs encode non-functional products. Even the main toxin groups are severely affected. For example, six neurotoxin genes and three $\mathrm{PLA}_{2}$ genes were truncated. Interestingly, entire families of metalloproteinases and CRISPs appear to be lost due to deletions and insertions. Although some of the long-chain neurotoxin genes encode full length functional proteins, there are some deletions at their Cterminal ends. These observations were made not only in singletons, but also in a number of clusters of toxin genes. In contrast none of the cellular transcripts (150 clones; $32 \%$ of cloned genes) showed deletions or insertions in nucleotide level. Thus, the only toxin cDNAs show this unusually high rate of deletions and insertions in A. labialis. The phenomenon of such high rate of accelerated insertions and deletions in only the toxin genes (described here) as with the accelerated evolution of exons of the toxin genes [62] will be of great interest.
Recently, we showed that in marbled sea snake (Aipysurus eydouxii) the only neurotoxin gene has a dinucleotide deletion resulting in the loss of viable neurotoxin [17]. This explains the 50- to 100-fold decrease in venom toxicity in comparison to that of other species in the same genus. We proposed that this loss could be a secondary result of the adaptation of Aipysurus eydouxii to a new dietary habit - feeding exclusively on fish eggs and, thus, the snake no longer requires its venom for prey capture [61]. Further, this snake is physically smaller in size compared to Aipysurus laevis. Similarly, venom of Austrelaps labialis is relatively less toxic compared to Austrelaps superbus and Austrelaps ramsayi. The $\mathrm{LD}_{50}$ of A. labialis $(1.3 \mathrm{mg} / \mathrm{kg})[8]$ is higher as compared to its close relative $A$. superbus whose $\mathrm{LD}_{50}$ is $0.5 \mathrm{mg} / \mathrm{kg}$ when injected subcutaneouly [2]. Further, A. labialis are smaller in size compared to others. Thus, rapid rate of deletions/insertions, as with accelerated evolution of toxin genes, may have significant influence in the evolution and survival of A. labialis. In a previous study, Chijiwa et al. [63] showed that the protein composition of venoms from Protobothrops flavoviridis (formerly Trimeresurus flavoviridis) of Okinawa island was different compared to that of snakes from the main island. In Okinawa snakes, some of the main components, such as myotoxic PLA 2 enzymes BPI and BPII, were absent. The genes encoding these proteins lost segments in their exon and intron and have become pseudogenes. This loss of BPI and BPII genes may not explain the overall decrease in the venom toxicity [63]. Interestingly, haemorrhagic metalloprotease, $\mathrm{HR}_{1 \mathrm{~b}}$ from the venom of Okinawa snakes is 10 fold less active. However, the reasons for this decrease in activity are not clearly understood. A detailed study of the entire transcriptome of their venom glands may help in understanding whether the observed regional variation in Okinawa snakes is similar to our findings with A. labialis snake. It would also be interesting to examine the transcriptome of $A$. labialis inhabiting the mainland to determine whether the observed accelerated deletions/ insertions in the genes of the Kangaroo Island inhabitant is also a regional variation.

Table I: Full length and truncated toxin genes found in the cDNA library of A. labialis venom gland.

\begin{tabular}{lccc}
\hline \multicolumn{1}{c}{ Protein family } & Number of genes & Full length genes & Truncated clones \\
\cline { 3 - 4 } & & & Deletion \\
\hline House keeping genes & & 16 & 0 \\
Neurotoxins & 16 & 13 & 0 \\
Kunitz-type protease inhibitors & 19 & 8 & 2 \\
PLA & 9 & 4 & 0 \\
C-type lectins & 7 & 1 & 2 \\
CRISPs & 1 & 0 & 0 \\
Metalloproteases & 6 & 0 & 3 \\
\hline
\end{tabular}




\section{Conclusion}

In the present study we have presented the toxin profile of A. labialis by constructing cDNA library using its venom gland tissue. Neurotoxin and $\mathrm{PLA}_{2}$ are the most abundant family of toxin in this snake venom. However it is interesting to note that some of the toxin transcripts have been found to be terminated prematurely either due to insertion or deletion of nucleotides. Due to these insertion and deletion some of the genes might not code for functional proteins. Such a higher rate of insertion and deletion might be responsible for its lower toxicity and play crucial role evolution of toxin genes.

\section{Authors' contributions}

RD and NNBT have and carried out the experiments, analyzed data and wrote the manuscript. AR has analyzed and interpreted the data. RMK is the principal investigator who designed the experiment, analyzed the data and critically reviewed the manuscript. All the authors have approved the final form of the manuscript.

\section{Additional material}

\section{Additional file 1}

Nucleotide sequences of long-chain neurotoxins showing insertions and deletions of nucleotides. Nucleotide sequences were aligned using ClustalW. Gaps are indicated with dots, insertion with arrow, deletion with asterisk and stop codon with square box.

Click here for file

[http://www.biomedcentral.com/content/supplementary/14712148-8-70-S1.pdf]

\section{Additional file 2}

Nucleotide sequences of $\mathrm{PLA}_{2}$ showing insertions and deletions of nucleotides. Nucleotide sequences were aligned using ClustalW. Gaps are indicated with dots, insertion with arrow and stop codon with square box. Click here for file

[http://www.biomedcentral.com/content/supplementary/14712148-8-70-S2.pdf]

\section{Additional file 3}

Nucleotide sequences of CRISPs showing insertions and deletions of nucleotides. Nucleotide sequences were aligned using ClustalW. Gaps are indicated with dots, insertion with arrow, deletion with asterisk and stop codon with square box.

Click here for file

[http://www.biomedcentral.com/content/supplementary/14712148-8-70-S3.pdf]

\section{Acknowledgements}

This work was supported from the grant (R-154-000-316-305) (to R.M. Kini) from Biomedical Research Council, Agency for Science, Technology and Research, Singapore.

\section{References}

I. Birrell GW, Earl ST, Wallis TP, Masci PP, de Jersey J, Gorman J], Lavin MF: The diversity of bioactive proteins in Australian snake venoms. Mol Cell Proteomics 2007, 6:973-986.

2. Broad AJ, Sutherland SK, Coulter AR: The lethality in mice of dangerous Australian and other snake venom. Toxicon 1979, 17:661-664.

3. Doery HM, Pearson JA: Haemolysins in venoms of Australian snakes. Observations on the haemolysins of the venoms of some Australian snakes and the separation of phospholipase A from the venom of Pseudechis porphyriacus. Biochem J 1961, 78:820-827.

4. Subburaju S, Kini RM: Isolation and purification of superbins I and II from Austrelaps superbus (copperhead) snake venom and their anticoagulant and antiplatelet effects. Toxicon 1997, 35: $1239-1250$.

5. Singh SB, Armugam A, Kini RM, Jeyaseelan K: Phospholipase A(2) with platelet aggregation inhibitor activity from Austrelaps superbus venom: protein purification and cDNA cloning. Arch Biochem Biophys 2000, 375:289-303.

6. Rehana S, Kini RM: Molecular isoforms of cobra venom factorlike proteins in the venom of Austrelaps superbus. Toxicon 2007, 50:32-52.

7. Shine R: Ecological ramifications of prey size: food habits and reproductive biology of Australian copperhead snakes (Austrelaps, Elapidae). Journal of Herpetology 1987, 2 I:71-74.

8. Sutherland SK: Genus Austrelaps Worrell, the Copperheads. In Australian Animal Toxins Melbourne: Oxford University Press; 1983:86-90.

9. $Y u$ Y, Breitbart M, McNairnie P, Rohwer F: FastGroupll: a webbased bioinformatics platform for analyses of large $16 \mathrm{~S}$ rDNA libraries. BMC Bioinformatics 2006, 7:57.

10. Thompson JD, Higgins DG, Gibson TJ: CLUSTAL W: improving the sensitivity of progressive multiple sequence alignment through sequence weighting, position-specific gap penalties and weight matrix choice. Nucleic Acids Res 1994, 22:4673-4680.

II. Clamp M, Cuff J, Searle SM, Barton GJ: The Jalview Java alignment editor. Bioinformatics 2004, 20:426-427.

12. Guindon S, Lethiec F, Duroux P, Gascuel O: PHYML Online - a web server for fast maximum likelihood-based phylogenetic inference. Nucleic Acids Res 2005, 33:W557-W559.

13. Kini RM: Molecular moulds with multiple missions: functional sites in three-finger toxins. Clin Exp Pharmacol Physiol 2002, 29:8I5-822.

14. Menez A: Functional architectures of animal toxins: a clue to drug design? Toxicon 1998, 36:1557-1572.

15. Tsetlin V: Snake venom alpha-neurotoxins and other 'threefinger' proteins. Eur J Biochem 1999, 264:28I-286.

16. Rajagopalan N, Pung YF, Zhu YZ, Wong PT, Kumar PP, Kini RM \{beta\}-Cardiotoxin: a new three-finger toxin from Ophiophagus hannah (king cobra) venom with beta-blocker activity. FASEB / 2007.

17. Li M, Fry BG, Kini RM: Eggs-only diet: its implications for the toxin profile changes and ecology of the marbled sea snake (Aipysurus eydouxii). J Mol Evol 2005, 60:8I-89.

18. Antil S, Servent D, Menez A: Variability among the sites by which curaremimetic toxins bind to torpedo acetylcholine receptor, as revealed by identification of the functional residues of alpha-cobratoxin. J Biol Chem 1999, 274:3485I-34858.

19. Antil-Delbeke S, Gaillard C, Tamiya T, Corringer PJ, Changeux JP, Servent $D$, Menez A: Molecular determinants by which a long chain toxin from snake venom interacts with the neuronal alpha 7-nicotinic acetylcholine receptor. J Biol Chem 2000, 275:29594-2960I.

20. Tamiya N, Maeda N, Cogger HG: Neurotoxins from the venoms of the sea snakes Hydrophis ornatus and Hydrophis lapemoides. Biochem J 1983, 213:3I-38.

21. Pillet L, Tremeau O, Ducancel F, Drevet P, Zinn-Justin S, Pinkasfeld S, Boulain JC, Menez A: Genetic engineering of snake toxins. Role of invariant residues in the structural and functional properties of a curaremimetic toxin, as probed by site-directed mutagenesis. J Biol Chem 1993, 268:909-916.

22. Tremeau O, Lemaire $C$, Drevet P, Pinkasfeld S, Ducancel F, Boulain JC, Menez A: Genetic engineering of snake toxins. The functional site of Erabutoxin a, as delineated by site-directed 
mutagenesis, includes variant residues. I Biol Chem 1995 270:9362-9369.

23. Schaloske RH, Dennis EA: The phospholipase A2 superfamily and its group numbering system. Biochim Biophys Acta 2006, | 76 I: | 246-1259.

24. Kini RM: Phospholipase A2 A Complex Multifunctional Protein Puzzle. In Venom Phospholipase A2 Enzymes: Structure, Function and Mechanism Edited by: Kini RM. Chichester, England: John Wiley \& Sons; 1997: I-28.

25. Gojobori T, Ikeo K: Molecular evolution of serine protease and its inhibitor with special reference to domain evolution. Philos Trans R Soc Lond B Biol Sci 1994, 344:4I I-4I 5

26. Laskowski $M$ Jr: Protein inhibitors of serine proteinases mechanism and classification. Adv Exp Med Biol 1986, I 99: I- I7.

27. Shafqat J, Zaidi ZH, Jornvall H: Purification and characterization of a chymotrypsin Kunitz inhibitor type of polypeptide from the venom of cobra (Naja naja naja). FEBS Lett 1990, 275:6-8.

28. Masci PP, Whitaker AN, Sparrow LG, de Jersey J, Winzor DJ, Watters DJ, Lavin MF, Gaffney PJ: Textilinins from Pseudonaja textilis textilis. Characterization of two plasmin inhibitors that reduce bleeding in an animal model. Blood Coagul Fibrinolysis 2000, I I:385-393.

29. Marlor CW, Delaria KA, Davis G, Muller DK, Greve JM, Tamburin PP: Identification and cloning of human placental bikunin, a novel serine protease inhibitor containing two Kunitz domains. I Biol Chem 1997, 272:12202-12208.

30. Delaria KA, Muller DK, Marlor CW, Brown JE, Das RC, Roczniak SO, Tamburini PP: Characterization of placental bikunin, a novel human serine protease inhibitor. I Biol Chem 1997 272:12209-12214.

31. Haendler B, Kratzschmar J, Theuring F, Schleuning WD: Transcripts for cysteine-rich secretory protein-I (CRISP-I; DE/AEG) and the novel related CRISP-3 are expressed under androgen control in the mouse salivary gland. Endocrinology 1993 , 133:192-198.

32. Yamazaki Y, Hyodo F, Morita T: Wide distribution of cysteinerich secretory proteins in snake venoms: isolation and cloning of novel snake venom cysteine-rich secretory proteins. Arch Biochem Biophys 2003, 4I 2:|33-|4I.

33. Osipov AV, Levashov MY, Tsetlin VI, Utkin YN: Cobra venom contains a pool of cysteine-rich secretory proteins. Biochem Biophys Res Commun 2005, 328: I77-I82.

34. Tu X, Wang J, Guo M, Zheng D, Teng M, Niu L, Liu Q, Huang Q, Hao $\mathrm{Q}$ : Purification, partial characterization, crystallization and preliminary $\mathbf{X}$-ray diffraction of two cysteine-rich secretory proteins from Naja atra and Trimeresurus stejnegeri venoms. Acta Crystallogr D Biol Crystallogr 2004, 60: I I08- I I I I.

35. Yamazaki Y, Brown RL, Morita T: Purification and cloning of toxins from elapid venoms that target cyclic nucleotide-gated ion channels. Biochemistry 2002, 4 I: I I33I-I I 337.

36. Brown RL, Haley TL, West KA, Crabb JW: Pseudechetoxin: a peptide blocker of cyclic nucleotide-gated ion channels. Proc Nat Acad Sci USA 1999, 96:754-759.

37. Matsui T, Fujimura Y, Titani K: Snake venom proteases affecting hemostasis and thrombosis. Biochim Biophys Acta 2000, | 477: |46-156.

38. Birrell GW, Earl ST, Wallis TP, Masci PP, de Jersey J, Gorman JJ, Lavin MF: The diversity of bioactive proteins in Australian snake venoms. Mol Cell Proteomics 2007, 6:973-986.

39. Bode W, Gomis-Ruth FX, Stockler W: Astacins, serralysins, snake venom and matrix metalloproteinases exhibit identical zinc-binding environments (HEXXHXXGXXH and Metturn) and topologies and should be grouped into a common family, the 'metzincins'. FEBS Lett 1993, 33 I: | 34- |40.

40. Hite LA, Jia LG, Bjarnason JB, Fox JW: cDNA sequences for four snake venom metalloproteinases: structure, classification, and their relationship to mammalian reproductive proteins. Arch Biochem Biophys 1994, 308: 182-191.

41. Bjarnason JB, Fox JW: Hemorrhagic metalloproteinases from snake venoms. Pharmacol Ther 1994, 62:325-372

42. Kamiguti AS, Hay CR, Theakston RD, Zuzel M: Insights into the mechanism of haemorrhage caused by snake venom metalloproteinases. Toxicon 1996, 34:627-642.

43. Gutierrez JM, Romero M, Nunez J, Chaves F, Borkow G, Ovadia M: Skeletal muscle necrosis and regeneration after injection of $\mathrm{BaHI}$, a hemorrhagic metalloproteinase isolated from the venom of the snake Bothrops asper (Terciopelo). Exp Mol Pathol 1995, 62:28-41.

44. Kamiguti AS: Platelets as targets of snake venom metalloproteinases. Toxicon 2005, 45:1041-1049.

45. Gutierrez JM, Romero M, Diaz C, Borkow G, Ovadia M: Isolation and characterization of a metalloproteinase with weak hemorrhagic activity from the venom of the snake Bothrops asper (terciopelo). Toxicon 1995, 33:19-29.

46. Moura-da-Silva AM, Laing GD, Paine MJ, Dennison JM, Politi V Crampton JM, Theakston RD: Processing of pro-tumor necrosis factor-alpha by venom metalloproteinases: a hypothesis explaining local tissue damage following snake bite. Eur J Immunol 1996, 26:2000-2005.

47. $\mathrm{Xu} \mathrm{Q}, \mathrm{Wu} X \mathrm{~F}, \mathrm{Xia} \mathrm{QC}, \mathrm{Wang} \mathrm{KY}$ : Cloning of a galactose-binding lectin from the venom of Trimeresurus stejnegeri. Biochem J 1999, 34 I (Pt 3):733-737.

48. Lu Q, Navdaev A, Clemetson JM, Clemetson KJ: Snake venom C type lectins interacting with platelet receptors. Structurefunction relationships and effects on haemostasis. Toxicon 2005, 45: 1089-1098.

49. Du XY, Clemetson JM, Navdaev A, Magnenat EM, Wells TN, Clemetson KJ: Ophioluxin, a convulxin-like C-type lectin from Ophiophagus hannah (King cobra) is a powerful platelet activator via glycoprotein VI. J Biol Chem 2002, 277:35 I24-35I 32.

50. Komori Y, Nikai T, Tohkai T, Sugihara H: Primary structure and biological activity of snake venom lectin (APL) from Agkistrodon p. piscivorus (Eastern cottonmouth). Toxicon 1999, 37:1053-1064.

51. Lin LP, Lin Q, Wang YQ: Cloning, expression and characterization of two C-type lectins from the venom gland of Bungarus multicinctus. Toxicon 2007, 50:4II-4I9.

52. Ogilvie ML, Dockter ME, Wenz L, Gartner TK: Isolation and characterization of lactose-binding lectins from the venoms of the snakes Lachesis muta and Dendroaspis jamesonii. J Biochem (Tokyo) 1986, I00:|425-|43|.

53. Zha HG, Lee WH, Zhang Y: Cloning of cDNAs encoding C-type lectins from Elapidae snakes Bungarus fasciatus and Bungarus multicinctus. Toxicon 2001, 39:1887-1892.

54. Birrell GW, Earl ST, Wallis TP, Masci PP, de Jersey J, Gorman JJ, Lavin MF: The diversity of bioactive proteins in Australian snake venoms. Mol Cell Proteomics 2007, 6:973-986.

55. Nikai T, Suzuki J, Komori Y, Ohkura M, Ohizumi Y, Sugihara H: Primary structure of the lectin from the venom of Bitis arietans (puff-adder). Biol harm Bull I995, I 8: I620-1622.

56. Kuai L, Fang F, Butler JS, Sherman F: Polyadenylation of rRNA in Saccharomyces cerevisiae. Proc Natl Acad Sci USA 2004, | 0 |:858|-8586

57. Decuypere S, Vandesompele J, Yardley V , De Donckeri S, Laurent T, Rijal S, Llanos-Cuentas A, Chappuis F, Arevalo J, Dujardin JC: Differential polyadenylation of ribosomal RNA during post-transcriptional processing in Leishmania. Parasitology 2005, | 3 |:32|-329.

58. Slomovic S, Laufer D, Geiger D, Schuster G: Polyadenylation of ribosomal RNA in human cells. Nucleic Acids Res 2006, 34:2966-2975.

59. Fry BG, Wuster W, Kini RM, Brusic V, Khan A, Venkataraman D, Rooney AP: Molecular evolution and phylogeny of elapid snake venom three-finger toxins. J Mol Evol 2003, 57:II0-129.

60. Ohno M, Menez R, Ogawa T, Danse JM, Shimohigashi Y, Fromen C Ducancel F, Zinn-Justin S, Le Du MH, Boulain JC, Tamiya T, Menez A: Molecular evolution of snake toxins: is the functional diversity of snake toxins associated with a mechanism of accelerated evolution? Prog Nucleic Acid Res Mol Biol 1998, 59:307-364.

61. Li M, Fry BG, Kini RM: Putting the brakes on snake venom evolution: the unique molecular evolutionary patterns of Aipysurus eydouxii (Marbled sea snake) phospholipase A2 toxins. Mol Biol Evol 2005, 22:934-94I.

62. Ohno M, Chijiwa T, Oda-Ueda N, Ogawa T, Hattori S: Molecular evolution of myotoxic phospholipases A2 from snake venom. Toxicon 2003, 42:84I-854.

63. Chijiwa T, Deshimaru M, Nobuhisa I, Nakai M, Ogawa T, Oda N, Nakashima K, Fukumaki Y, Shimohigashi Y, Hattori S, Ohno M Regional evolution of venom-gland phospholipase $A 2$ isoenzymes of Trimeresurus flavoviridis snakes in the southwestern islands of Japan. Biochem J 2000, 347:49 |-499. 
64. Walkinshaw MD, Saenger W, Maelicke A: Three-dimensional structure of the "long" neurotoxin from cobra venom. Proc Natl Acad Sci USA 1980, 77:2400-2404.

65. Fujimi TJ, Nakajyo T, Nishimura E, Ogura E, Tsuchiya T, Tamiya T: Molecular evolution and diversification of snake toxin genes, revealed by analysis of intron sequences. Gene 2003, 313:111-II8.

66. St Pierre L, Woods R, Earl S, Masci PP, Lavin MF: Identification and analysis of venom gland-specific genes from the coastal taipan (Oxyuranus scutellatus) and related species. Cell Mol Life Sci 2005, 62:2679-2693.

67. Guimaraes-Gomes $\mathrm{V}$, Oliveira-Carvalho $\mathrm{AL}$, Junqueira-de-Azevedo IL, DL SD, Pujol-Luz M, Castro HC, Ho PL, Zingali RB: Cloning, characterization, and structural analysis of a $C$-type lectin from Bothrops insularis (BiL) venom. Arch Biochem Biophys 2004, 432: I-II.

Publish with Bio Med Central and every scientist can read your work free of charge

"BioMed Central will be the most significant development for disseminating the results of biomedical research in our lifetime. "

Sir Paul Nurse, Cancer Research UK

Your research papers will be:

- available free of charge to the entire biomedical community

- peer reviewed and published immediately upon acceptance

- cited in PubMed and archived on PubMed Central

- yours - you keep the copyright 